\title{
Hurricane track variability and secular potential intensity trends
}

\author{
James P. Kossin • Suzana J. Camargo
}

Received: 26 June 2009 / Accepted: 16 September 2009 / Published online: 21 October 2009

(C) The Author(s) 2009. This article is published with open access at Springerlink.com

\begin{abstract}
Sea surface temperature in the tropical North Atlantic has been shown to co-vary with hurricane activity on a broad range of time-scales. One general hypothesis for this observed relationship is based on the theory of potential intensity (PI) whereby the local ambient environment determines the maximum intensity that a hurricane can achieve. Under this theory, climate change and resultant changes in PI can affect the distribution of hurricane intensities by modulating the upper extreme values. Indeed, PI averaged over the tropical North Atlantic during the hurricane season has been increasing in concert with sea surface temperature, which introduces an expectation for a secular upward shift in the distribution of hurricane intensities. However, hurricane tracks also largely determine the local storm-ambient environment and thus track variability introduces additional ambient PI variability. Here we show that this additional variance removes the observed secular trend in mean summertime tropical North Atlantic PI, and there is no tacit expectation that hurricanes have become stronger based solely on PI theory. The observed trends in integrated metrics such as hurricane power dissipation are then more likely to be caused by changes in storm frequency and duration due to broader scale regional variability than secular intensity changes due solely to ambient thermodynamics.
\end{abstract}

\section{Introduction}

Hurricanes may be broadly viewed as heat engines that convert available ambient thermodynamic energy to wind. The conversion is based on the liberation of large

J. P. Kossin (凶)

NOAA's National Climatic Data Center, University of Wisconsin, 1225 W. Dayton St., Madison, WI 53706, USA

e-mail: james.kossin@noaa.gov

S. J. Camargo

Lamont-Doherty Earth Observatory, Columbia University, Palisades, NY, USA 
amounts of latent heat found in the moist tropical atmosphere, which locally warms the atmosphere, lowering sea level pressure and causing air near the surface to spiral inwards toward the low-pressure center. As the air spirals inward, it sequesters additional moist energy from the underlying sea surface and the process can amplify through this positive feedback (Emanuel 1986). Within this framework, a well-known theory has been developed that sets an upper bound on the maximum intensity that a hurricane can achieve (Emanuel 1988; Holland 1997). This "potential intensity" is defined strictly by the local ambient thermodynamic conditions surrounding an existing storm and is based on factors that can be directly measured with existing temperature and moisture data.

In the absolute context of potential intensity (PI) theory, the expected response of hurricane intensity to observed climate change is straightforward: if climate change causes an increase in the ambient PI that hurricanes move through, the distribution of intensities in a representative sample of storms will shift toward greater intensities (Emanuel 2000; Wing et al. 2007). Such a shift in the distribution would be most evident at the upper quantiles of the distribution as the strongest hurricanes become stronger (Elsner et al. 2008).

Underlying sea surface temperature (SST) is a dominant factor in determining PI and they strongly co-vary (DeMaria and Kaplan 1994). Both SST and PI have been markedly increasing in the summertime tropical North Atlantic since ca. 1980 (Fig. 1) and a shift has been observed in the hurricane intensity distribution over this same period (Elsner et al. 2008). However, it is not manifest that the former may be implicated as cause for the latter because the thermodynamic control of hurricanes occurs locally within the ambient environment of a storm, and regional averages of PI are not tacitly relevant.

Here we will demonstrate, in agreement with Wing et al. (2007), that the observed inter-annual to decadal variability of the local ambient environment of hurricanes differs significantly from the regionally and temporally averaged environment, and the relevant metric of local PI is sensitive to hurricane track variability in addition to regional climatic changes. In particular, we will show that the additional variance introduced by track variability effectively overwhelms the secular trend in regional PI observed in the present historical record. This suggests that the observed secular increase in North Atlantic hurricane power dissipation (Emanuel 2005) should not be explicitly considered in the local framework of PI theory, and the relationship between power dissipation and changes in the mean tropical North Atlantic thermodynamic fields are likely due to broader regional influences on hurricane frequency and duration.

\section{Hurricane tracks and potential intensity variability}

Hurricane tracks vary in both space and time. The official North Atlantic hurricane season spans June-November, and the genesis locations and subsequent tracks of hurricanes are observed to occur over a broad area of the ocean basin. Figure 2 shows the mean climatological fields of PI and SST during the most active part of the hurricane season (Aug-Oct) with a random sample of hurricane tracks superimposed. Because SST and PI fields have coherent spatial gradients, stormambient SST and PI is a strong function of track, and the along-track environment 
Fig. 1 (a) Potential intensity $\left(\mathrm{PI}, \mathrm{m} \mathrm{s}^{-1}\right.$ ) and (b) sea surface temperature $\left(\mathrm{SST},{ }^{\circ} \mathrm{C}\right)$ averaged over the tropical North Atlantic (tNA) during Aug-Oct (ASO). The bold lines result from application of a centered 5-year moving window filter to the raw time series. The SST data span the period 1854-2008, and the PI data span the period 1948-2008 (see Section 4 for details)

Fig. 2 Average

August-October potential intensity (a) and sea surface temperature (b). A random draw of 100 hurricane tracks is superimposed on the SST field. The different hurricanes move through significantly different ambient environments during their lifetimes
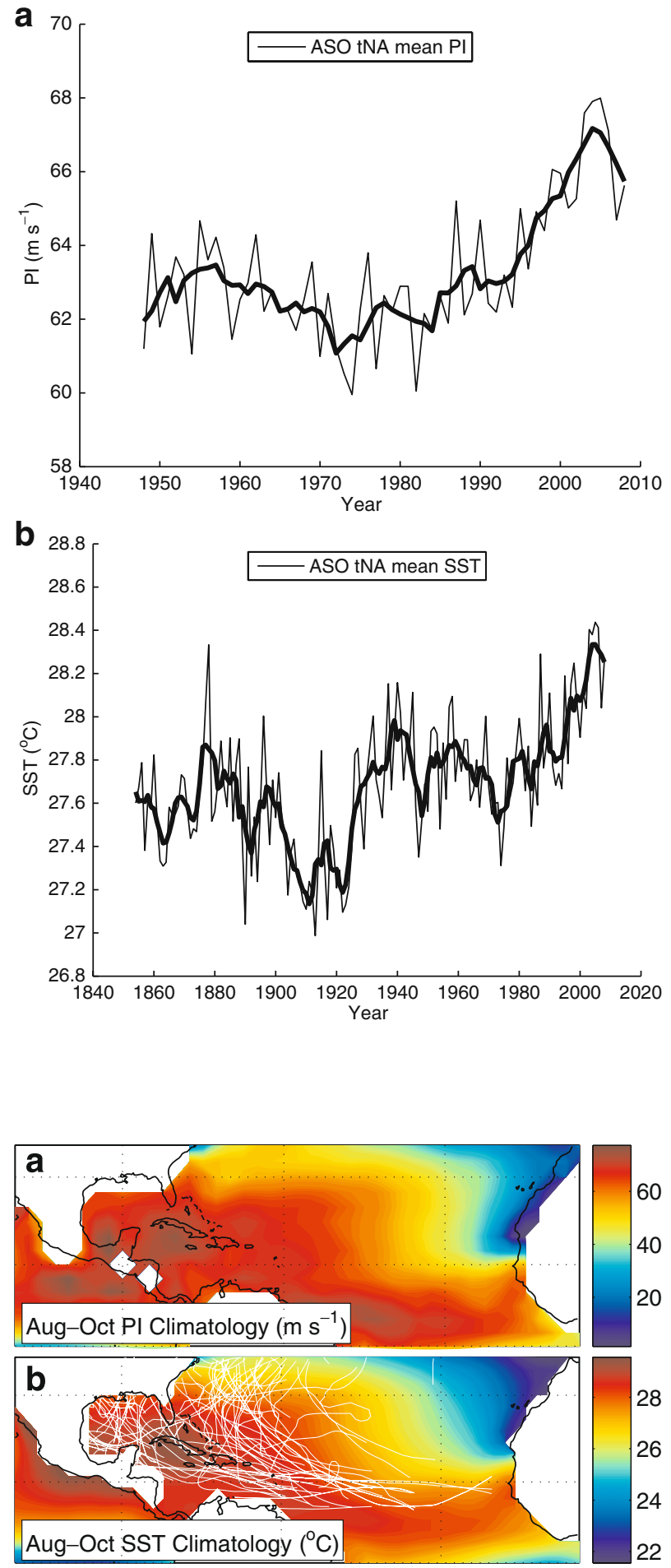
varies markedly among the individual tracks shown in Fig. 2. In addition to spatial variability, intra-seasonal variability of the environment and storm-tracks introduces further variance to the mean storm-ambient conditions.

When considering the maximum intensity that a hurricane achieves in its lifetime, the most critical period during its evolution begins when it reaches tropical storm strength $\left(17 \mathrm{~m} \mathrm{~s}^{-1}\right)$ and officially becomes a "named storm", and ends when the storm reaches its lifetime maximum intensity. It is during this period that ambient PI may limit the intensification process and constrain the lifetime maximum intensity of the storm. When this period is considered for each storm in the historical record, the ambient PI averaged along the individual storm tracks is highly variable. Among the 434 storms that achieved their lifetime maximum intensity in the tropical North Atlantic during the period 1948-2008, their mean ambient PI is $66 \mathrm{~m} \mathrm{~s}^{-1}$ with a standard deviation of $8 \mathrm{~m} \mathrm{~s}^{-1}$.

When annual averages of storm-ambient PI and SST are formed (details in Section 4), the additional variance introduced by the inter-annual track variability significantly flattens the regional PI and SST trends seen in Fig. 1. This is demonstrated by the red curves in Fig. 3, which show the time series of annually averaged storm-ambient PI and SST directly beneath the storm. A linear least-squares fit of the regional-mean PI time series (black curve, Fig. 3a) contains a highly significant trend with amplitude $0.6 \mathrm{~m} \mathrm{~s}^{-1}$ per decade $\left(p\right.$ value $\left.=10^{-5}\right)$. When the additional variance due to track variability is included, a linear fit of the storm-ambient PI time series (red curve, Fig. 3a) contains no significant trend ( $p$ value $=0.25$ ). To better quantify the variability of the storm-ambient fields due to track variability, the blue curves in Fig. 3 show the mean ambient PI and underlying SST when the along-track averages are taken within the climatological fields. That is, the blue curves show how the annual mean storm-ambient conditions vary due purely to interannual track variability. The marked increases since ca. 1980 are still evident in both ambient PI and underlying SST (red curves), congruent with the results of Elsner et al. (2008), but the shift toward regions of cooler climatological SST (blue curve, Fig. 3b), which has persisted since the late 1970's, has counteracted the regional increases. In this case, the unprecedented maximum observed in the present values of tropical-mean SST (black curve, Fig. 3b) is not unprecedented in terms of the actual storm environment, and similarly high ambient SST is observed ca. 1940 (red curve, Fig. 3b).

To better understand the source of the track-related variability of storm-ambient PI and SST, Fig. 4 compares tracks for two periods. The period 1943-1947 is a period of higher mean ambient PI and warmer underlying SST, while 1957-1962 is a period of lower ambient PI and cooler SST. It is clear that the difference in the mean storm environments between the two periods is due to the occurrence of proportionally more storm tracks in the lower PI region east of $60^{\circ} \mathrm{W}$ longitude (Fig. 2). These two periods were chosen since they are both within the era between the introduction of aircraft reconnaissance into hurricanes and the introduction of satellite data, and it is less likely that the difference in tracks is an artifact of data heterogeneity (e.g., Landsea 2007). Analogous results are found when other periods of alternating high and low mean ambient PI are compared although the eastward track shift responsible for the abrupt change in storm-ambient conditions in the 1970's may be due in part to the contemporaneous introduction of geostationary satellite data, which increase the likelihood of identifying these far-eastern storms. Still, the data are suggestive 
Fig. 3 Time series of annually averaged storm-ambient PI (a) and SST directly under the storm (b). Red curves represent actual values and blue curves represent hypothetical values if the storm tracks moved through the climatological fields. For each storm, only the period from tropical storm strength to lifetime maximum intensity is considered. The curves from Fig. 1 representing the mean summertime (ASO) tropical North Atlantic (tNA) PI and SST are re-displayed here (in black) for comparison. As in Fig. 1, bold lines result from application of a centered 5-year moving window filter to the raw time series

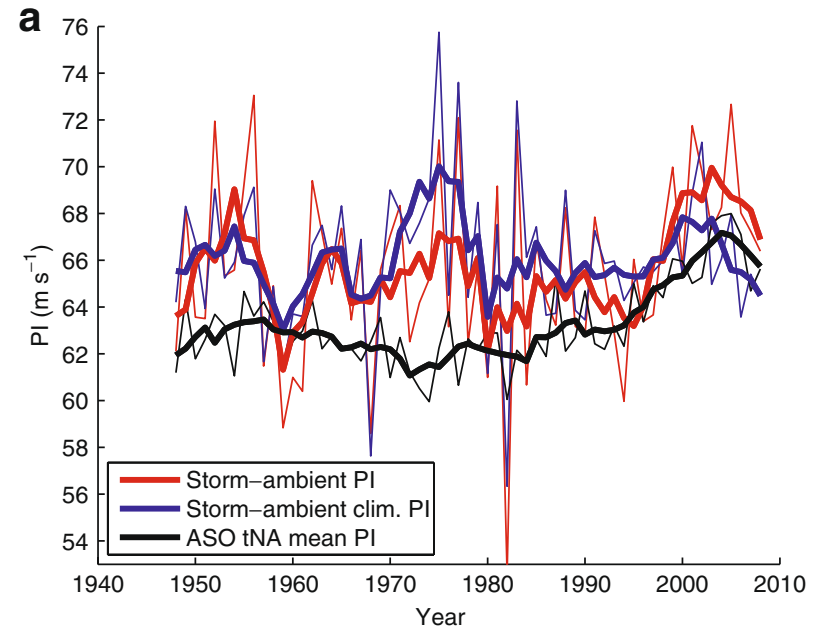

b

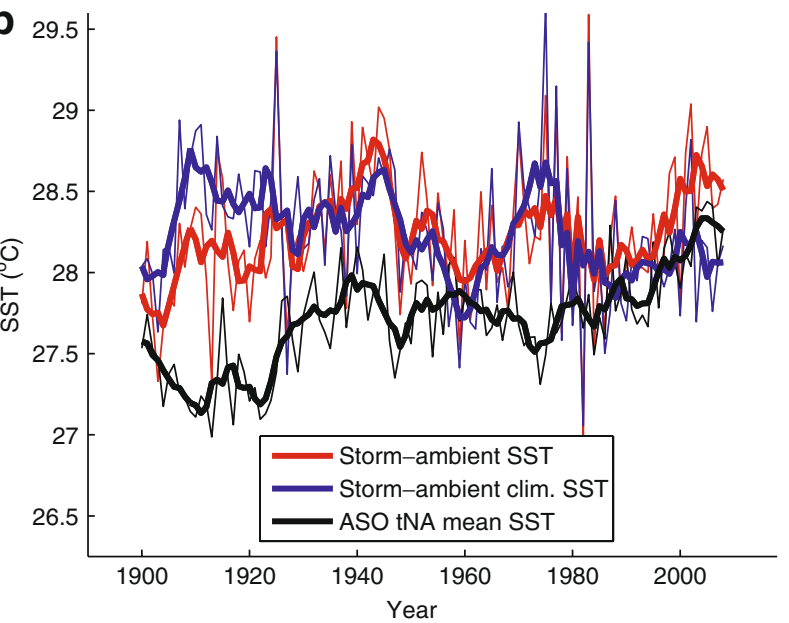

that much of the track variability responsible for the variability in the storm-ambient conditions is due to persistent track shifts into and out of the easternmost part of the North Atlantic. Coherent track shifts have been previously noted and related to tropical North Atlantic climate variability (Elsner 2003; Kimberlain and Elsner 1998;

Fig. 4 Tracks, from first instance of tropical storm intensity to lifetime-maximum intensity, observed south of $30^{\circ} \mathrm{N}$ latitude during the periods 1943-1947 (red, 39 storms) and 1957-1962 (blue, 36 storms) $90^{\circ} \mathrm{W}$ $60^{\circ} \mathrm{W}$ $30^{\circ} \mathrm{W}$

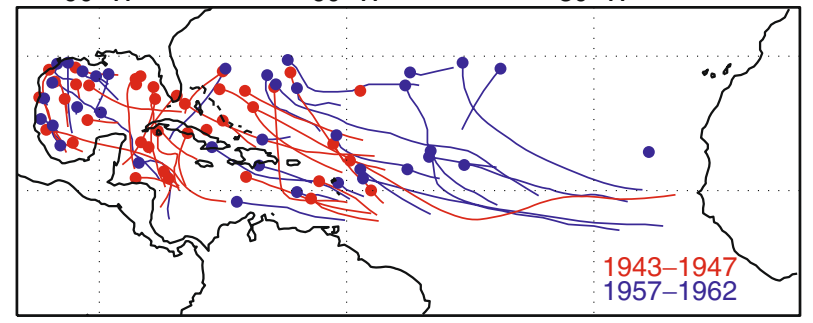


Xie et al. 2005; Kossin and Vimont 2007; Holland and Webster 2007; Holland 2007), although it is not clear to what degree these shifts are stochastic in nature.

When the ambient climatological conditions are subtracted from the actual ambient conditions to form the storm-ambient anomalous conditions, the time series for both PI and SST closely follow the regionally averaged anomalies (Fig. 5). This demonstrates that the storm-ambient conditions are experiencing the same variability and secular trends as the tropical mean environment, but the inclusion of the track variability largely removes the regional trend signal. While the secular trends of mean PI and SST in the summertime tropical North Atlantic are indeed projecting onto the storm-ambient conditions, the observed changes in actual ambient thermodynamic conditions over the past 60 years do not, by themselves, lead to an expectation for a secular change in the historical distribution of hurricane intensities.

Fig. 5 Time series of PI (a) and SST (b) anomaly. The red curves show the anomalous storm-ambient conditions, and the blue curves show the regional-mean tropical North Atlantic (tNA) Aug-Oct (ASO) anomalies. Here the red curves are simply the difference between the red and blue curves in Fig. 3. The blue curves are identical to the curves in Fig. 1 but with the subtraction of their long-term means
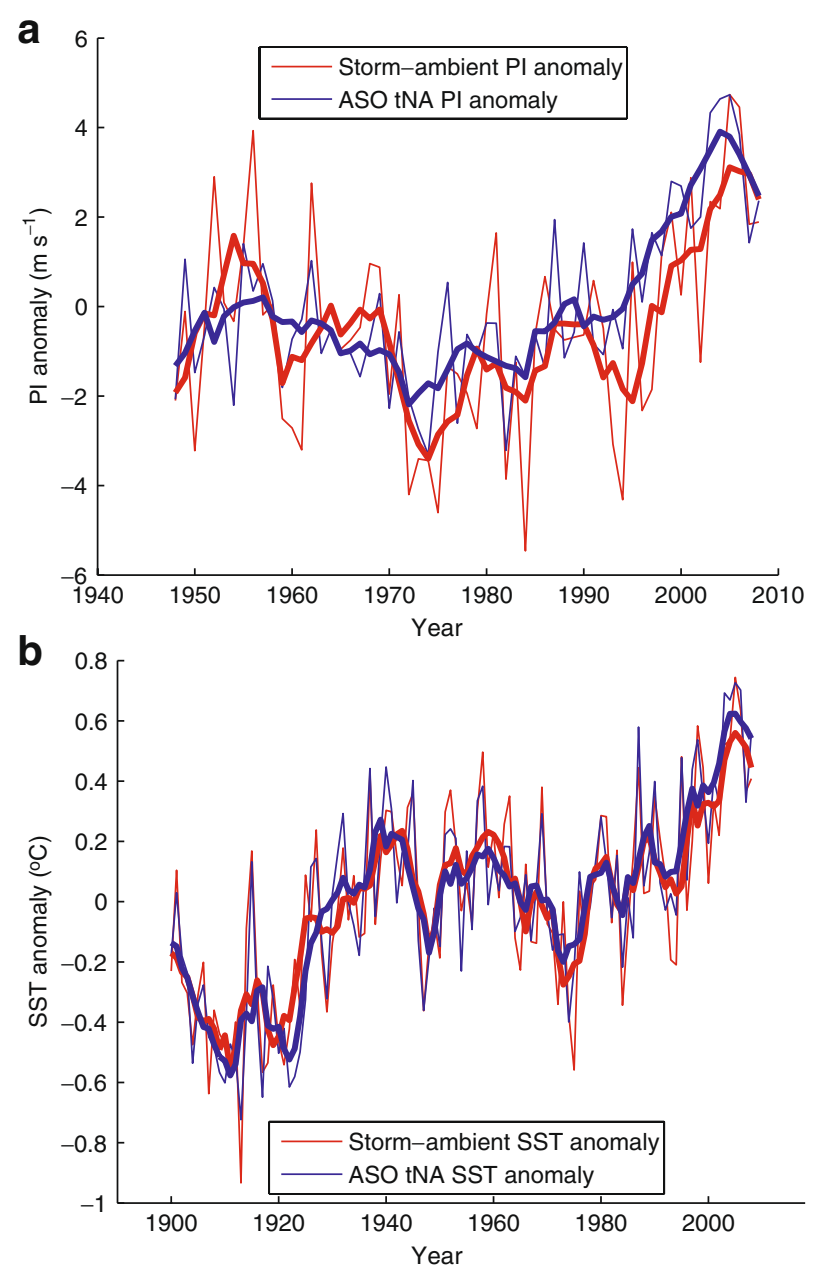


\section{Discussion}

Changes in hurricane intensity, frequency, genesis location, duration, and track contribute to what is sometimes broadly defined as "hurricane activity". Of these metrics, intensity has the most direct physically reconcilable link to climate variability (within the framework of potential intensity theory). Statistical correlations between necessary ambient environmental conditions and tropical cyclogenesis frequency have been well documented (DeMaria et al. 2001), but these relationships are less formally based on physical arguments and may be neither stationary in time nor independent of other factors (Nolan et al. 2007; Knutson et al. 2008). Similarly, the pathways through which climate variability can affect hurricane genesis position, duration, and tracks are not well understood, and guidance from dynamical models is still limited, but statistical correlations have been identified and hypotheses have been formulated (Elsner 2003; Xie et al. 2005; Kossin and Vimont 2007).

Further complication in determining cause and effect arises from the strong relationship between intensity and duration (Kossin and Vimont 2007). Since hurricanes moving through a favorable environment intensify at an average rate of about $12 \mathrm{~m} \mathrm{~s}^{-1}$ per day (Emanuel 2000), the lifetime maximum intensity of a storm depends on its duration, which can depend on its genesis location. There are then three distinct, but not mutually exclusive pathways to inducing an upward shift in a distribution of hurricane intensities: increasing mean ambient PI, increasing mean intensification rate, or increasing the mean duration of the intensification periods. The first is more easily linked to climate and tested in a numerical or theoretical framework, but the mechanistic links to relate the latter two to climate variability are significantly more difficult to uncover.

The results presented here suggest that the observed trends in measures of hurricane activity such as power dissipation or accumulated cyclone energy (Emanuel 2005; Bell and Cheliah 2006) should not be explicitly considered within the framework of potential intensity theory, and are more relevantly related to frequency and track changes. This hypothesis is based on our limited historical data in which the introduction of track variability is enough to dominate the broader scale regional PI trend. There is no expectation that track changes can indefinitely counteract the regional trend if it continues.

\section{Data and methods}

Potential intensity was calculated from the daily NCEP/NCAR reanalysis data (Kalnay et al. 1996) and monthly NOAA Extended Reconstructed V3 SST data (Smith et al. 2008) following the method of Bister and Emanuel (1998). Monthly (daily) climatology maps of SST (PI) were constructed for the period 1854-2008 (1980-2008). The mean summertime tropical North Atlantic (tNA) SST and PI values were calculated over Aug-Oct (ASO) in the region $5-25^{\circ} \mathrm{N}$ latitude and 20-90 $\mathrm{W}$ longitude. The results presented here are not sensitive to this choice of averaging boundaries.

Storm-ambient PI and SST were calculated using monthly SST and daily reanalysis data bi-linearly interpolated to a single point at the reported center of the storms. The center positions are recorded every $6 \mathrm{~h}$ during the life of each storm. For each 
storm, we only considered the intensification period from tropical storm strength (first instance of $17 \mathrm{~m} \mathrm{~s}^{-1}$ intensity) to the lifetime maximum intensity, and required that this portion of the track remain south of $30^{\circ} \mathrm{N}$ latitude. If a storm achieved its lifetime maximum intensity more than once, we only considered the first occurrence (cf. Wing et al. 2007).

To reduce the effects that the storms themselves have on the reanalysis fields (Hart et al. 2007), we used the PI values 5 days prior to the arrival of the storm. The results are not sensitive to this procedure, and it serves only to reduce a stationary bias relative to climatology. It is also well known that storms have a short-term cooling effect on underlying SST (e.g., Stramma et al. 1986), and there is potential for monthly SST data to have a cold bias along the storm tracks. However, the very close agreement between the tropical mean and the storm-ambient SST anomalies (Fig. 5b) suggests that the storm-ambient fields deduced from monthly mean SST fields are not substantially affected by this.

Prior to 1900, the small number of detected and recorded storms in the historical data introduces potential sampling issues and the annual mean ambient SST time series in Fig. 3b are constrained to the period 1900-2008. The reanalysis data required to calculate PI is available for 1948-2008. Following Emanuel (2007) and Wing et al. (2007), pre-1979 PI values were adjusted with an additive constant of $-1.9 \mathrm{~m} \mathrm{~s}^{-1}$. Removal of this adjustment has little effect on our main conclusions, but it should be noted that the fidelity of the PI time series shown here most likely suffers from inconsistencies, particularly from potentially inaccurate upper-level atmospheric temperature data in the reanalysis fields (e.g., Allen and Sherwood 2008), and the simple adjustment used here is unlikely to mitigate these issues completely.

Acknowledgements We have benefited from discussions with Kerry Emanuel, Robert Hart, Daniel Vimont, and Michael Mann. ERSST V3 and NCEP Reanalysis data were provided by the NOAA/OAR/ESRL PSD, Boulder, Colorado, USA, from their Web site at http://www.cdc. noaa.gov/. SJC acknowledges support from NOAA grant NA08OAR4320912.

Open Access This article is distributed under the terms of the Creative Commons Attribution Noncommercial License which permits any noncommercial use, distribution, and reproduction in any medium, provided the original author(s) and source are credited.

\section{References}

Allen RJ, Sherwood SC (2008) Warming maximum in the tropical upper troposphere deduced from thermal winds. Nat Geosci 1:399-403. doi:10.1038/ngeo208

Bell DB, Cheliah M (2006) Leading tropical modes associated with interannual and multidecadal fluctuations in North Atlantic hurricane activity. J Climate 19:590-612

Bister M, Emanuel KA (1998) Dissipative heating and hurricane intensity. Meteorol Atmos Phys 52:233-240

Demaria M, Kaplan J (1994) Sea surface temperature and the maximum intensity of Atlantic tropical cyclones. J Climate 7:1324-1334

DeMaria M, Knaff JA, Connell BH (2001) A tropical cyclone genesis parameter for the tropical Atlantic. Weather Forecast 16:219-233

Elsner JB (2003) Tracking hurricanes. Bull Am Meteorol Soc 84:353-356

Elsner JB, Kossin JP, Jagger TH (2008) The increasing intensity of the strongest tropical cyclones. Nature 455:92-95

Emanuel KA (1986) An air-sea interaction theory for tropical cyclones. Part I: Steady state maintenance. J Atmos Sci 43:585-604

Emanuel KA (1988) The maximum intensity of hurricanes. J Atmos Sci 45:1143-1155 
Emanuel KA (2000) A statistical analysis of hurricane intensity. Mon Weather Rev 128:1139-1152

Emanuel KA (2005) Increasing destructiveness of tropical cyclones over the past 30 years. Nature 436:686-688

Emanuel K (2007) Environmental factors affecting tropical cyclone power dissipation. J Climate 20:5497-5509

Hart RE, Maue RN, Watson MC (2007) Estimating local memory of tropical cyclones through MPI anomaly evolution. Mon Weather Rev 135:3990-4005

Holland GJ (1997) The maximum potential intensity of tropical cyclones. J Atmos Sci 54:2519-2541

Holland GJ (2007) Misuse of landfall as a proxy for Atlantic tropical cyclone activity. Eos Trans AGU 88(36):349. doi:10.1029/2007EO360001

Holland GJ, Webster PJ (2007) Heightened tropical cyclone activity in the North Atlantic: natural variability or climate trend? Philos Trans R Soc A 365:2695-2716

Kalnay E et al (1996) The NCEP/NCAR 40-year reanalysis project. Bull Am Meteorol Soc 77: 437-471

Kimberlain TB, Elsner JB (1998) The 1995 and 1996 North Atlantic hurricane seasons: a return to the tropical-only hurricane. J Climate 11:2062-2069

Knutson TR, Sirutis JJ, Garner ST, Vecchi GA, Held IM (2008) Simulated reduction in Atlantic hurricane frequency under twenty-first-century warming conditions. Nat Geosci. doi:10.1038/ ngeo202

Kossin JP, Vimont DJ (2007) A more general framework for understanding Atlantic hurricane variability and trends. Bull Am Meteorol Soc 88:1767-1781

Landsea CW (2007) Counting Atlantic tropical cyclones back to 1900. Eos Trans AGU 88(18). doi:10.1029/2007EO180001

Nolan DS, Rappin ED, Emanuel KA (2007) Tropical cyclogenesis sensitivity to environmental parameters in radiative-convective equilibrium. Q J R Meteorol Soc 133:2085-2107

Smith TM, Reynolds RW, Peterson TC, Lawrimore J (2008) Improvements to NOAA's historical merged land-ocean surface temperature analysis (1880-2006). J Climate 21:2283-2296

Stramma RS, Cornillon P, Price JF (1986) Satellite observation of sea surface cooling by hurricanes. J Geophys Res 91:5031-5035

Wing AA, Sobel AH, Camargo SJ (2007) Relationship between the potential and actual intensities of tropical cyclones on interannual time scales. Geophys Res Lett 34:L08810. doi:10.1029/ 2006GL028581

Xie L, Yan T, Pietrafesa LJ, Morrison JM, Karl T (2005) Climatology and interannual variability of North Atlantic hurricane tracks. J Climate 18:5370-5381 